\title{
Evaluación de la actividad proteolítica y lipolítica de cepas para el tratamiento de efluentes de curtiembre
}

\section{RESUMEN}

Los efluentes investigados poseen una elevada DBO (Demanda Bioquímica de Oxígeno) representada principalmente por proteínas y lípidos; lo cual motivó la búsqueda de microorganismos con capacidades proteolíticas y lipolíticas, para un potencial tratamiento biológico de dichos efluentes.

Se seleccionaron 39 cepas para los ensayos, de estas, el $41 \%$ resultaron positivas para actividad proteolítica, $51 \%$ para actividad lipolítica y $38 \%$ para ambas actividades; asimismo el $100 \%$ crecieron en $\mathrm{pH} 9$ y 10 , el $79.5 \%$ en $\mathrm{pH} 11$ y el $54 \%$ en pH 12. Cabe resaltar que del total de cepas ensayadas dos de ellas (N3D y N4E) presentaron las mejores actividades proteolíticas y lipolíticas respectivamente. Se concluye que en los efluentes de curtiembre existen microorganismos con un alto potencial enzimático de bioconversión.

Palabras clave: alcalino, bioconversión, curtiembre, efluente, lipolítico, proteolítico

EVALUATION PROTEOLYTIC AND LIPOLYTIC ACTIVITY OF STRAINS FOR THE TREATMENT OF TANNERY EFFLUENTS

\section{ABSTRACT}

The investigated effluents have a high BOD (Biochemical Oxygen Demand) represented mainly by proteins and lipids ; which motivated the search for microorganisms with proteolytic and lipolytic capabilities for a potential biological treatment of these effluents.

39 strains were selected for testing, of these, $41 \%$ were positive for proteolytic activity, lipolytic activity to $51 \%$ and $38 \%$ for both activities; also grew $100 \%$ in $\mathrm{pH} 9$ and $10,79.5 \%$ in $\mathrm{pH} 11$ and $54 \%$ at $\mathrm{pH} 12$ is worth noting that of all strains tested two (N3D and N4E) presented the best proteolytic and lipolytic activities respectively. We conclude that in tannery effluents are microorganisms with high enzymatic potential of bioconversion.

Keywords: alkaline, bioconversion, effluent, lipolytic, proteolytic, tannery

\section{INTRODUCCIÓN}

En el Reporte Técnico para la Industria de Curtiembres en el Perú para el Ministerio de Industria, Turismo, Integración y Comercio Internacional (MITINCI) Technical Assistance Provider (TAP) Proyecto SENREM (CONAM - USAID) Stuart Miller y colaboradores sostienen que en el Perú sobre todo en ciudades donde el crecimiento de industrias es vertiginoso se nota, muy claramente, un crecimiento en los niveles de contaminación de los ecosistemas aledaños por la descarga de los efluentes industriales sin tratamiento previo ni control adecuado de las autoridades correspondientes.

A pesar de que el Perú posee legislación para el control de los efluentes industriales, lamentablemente no se realiza un control estricto a todas las industrias por razones económicas, técnicas, administrativas entre otras. El problema se agrava por el incremento de pequeñas y m+edianas industrias informales que al no estar registradas evaden dicho control, contribuyendo negativa y clandestinamente a la contaminación del efluente (Stuart, 1999).

El convenio entre el Centro Panamericano de Ingeniería Sanitaria y Ciencias del Ambiente (CEPIS) y la Agencia de Cooperación Técnica (GTZ) de la República de Alemania realizaron un estudio de las curtiembres en la zona norte del Perú y llegaron a la conclusión que actualmente el sector curtiembre genera un serio problema ambiental en la contaminación de los cuerpos de agua por la descarga de altas concentraciones de materia orgánica, sulfuro y cromo, descargas que se realizan directamente a los desagües y/o ríos, lagos, etc. Entre las causas más destacables de esta situación se encuentran el aumento de la micro y pequeña industria del cuero, uso de tecnologías obsoletas y deterioro paulatino de grandes curtiembres. De otro lado, ninguna curtiembre es lo suficientemente grande para justificar el gasto de instalación de un sistema completo de tratamiento de efluentes y residuos.

Los análisis realizados a estos efluentes revelan un alto valor de la demanda bioquímica de oxígeno, así como de sólidos totales lo cual demuestra su elevado potencial contaminante. Estudios realizados a nivel de laboratorio, referente al tratamiento de estos efluentes concluyen en la factibilidad de estos procesos; sin embargo representan costos significativos y que difícilmente

Docente Principal de la Facultad de Ciencias Biológicas. UNMSM.

E-mail: biomac_20@hotmail.com 
son asumidos por el empresario, porque considera un egreso "innecesario" que mermaría sus cálculos de ganancia, debido a que desconoce el enorme daño que causa al ecosistema y que dañar el medio ambiente repercutirá directa o indirectamente sobre su empresa.

Asimismo los empresarios de curtiembres se encuentran preocupados por las exigencias de las nuevas disposiciones y normas legales que obligan a las empresas a cumplir con los valores máximos admisibles (VMA) de las descargas de aguas residuales no domésticas en el sistema de alcantarillado (Decreto Supremo $\mathrm{N}^{\circ} 1$ 021-2009-VIVIENDA) (Decreto Supremo 003-2002-PRODUCE) bajo pena de ingentes multas, suspensión de servicio o cierre de planta. En tal sentido la presente investigación formula el problema general:

Afrontar el problema planteado no pasa solamente por el control, supervisión y sanción de las empresas generadoras de efluentes sino también por la investigación y presentación de nuevas alternativas cada vez más factibles y baratas de tratamiento o reciclaje de dichos efluentes, que puedan ser adoptadas por las industrias implicadas, tales como los bioprocesos que representan en sí una opción tecnológica de menor impacto ambiental.

El tratamiento biológico de efluentes industriales ha cobrado tanta importancia que se ha hecho imprescindibleenlagestión deefluentes; sinembargo requiere de la búsqueda de microorganismos con potencial de bioconversión, entrenados y adaptados a las condiciones fisicoquímicas estresantes del efluente como la alcalinidad y concentraciones altas de sodio, por ello es necesario caracterizar previamente los efluentes para diseñar el tipo y las condiciones de tratamiento.

\section{MARCO TEÓRICO}

\subsection{Depuraciones con sistemas biológicos biológicos (Lawrence, 2008)}

Constituyen una serie de importantes procesos de tratamiento que tienen en común la utilización de microorganismos (entre las que destacan las bacterias) para llevar a cabo la eliminación de componentes indeseables del agua, aprovechando la actividad metabólica de los mismos sobre esos componentes. La aplicación tradicional consiste en la eliminación de materia orgánica biodegradable, tanto soluble como coloidal, así como la eliminación de compuestos que contienen elementos nutrientes ( $\mathrm{N}$ y $\mathrm{P}$ ). Es uno de los tratamientos más habituales, no solo en el caso de aguas residuales urbanas, sino en buena parte de las aguas industriales. En la mayor parte de los casos, la materia orgánica constituye la fuente de energía y de carbono que necesitan los microorganismos para su crecimiento. Además, también es necesaria la presencia de nutrientes, que contengan los elementos esenciales para el crecimiento, especialmente los compuestos que contengan $\mathrm{N}$ y $\mathrm{P}$, y por último, en el caso de sistema aerobio, la presencia de oxígeno disuelto en el agua. Este último aspecto será clave a la hora de elegir el proceso biológico conveniente.

En el metabolismo bacteriano juega un papel fundamental el elemento aceptor de electrones en los procesos de oxidación de la materia orgánica. Este aspecto, además, tiene una importante incidencia en las posibilidades de aplicación al tratamiento de aguas. Atendiendo a cual es dicho aceptor de electrones distinguimos tres casos:

Sistemas aerobios: La presencia de $\mathrm{O}_{2}$ hace que este elemento sea el aceptor de electrones, por lo que se obtienen unos rendimientos energéticos elevados, provocando una importante generación de fangos, debido al alto crecimiento de las bacterias aerobias. Su aplicación a aguas residuales puede estar muy condicionada por la baja solubilidad del oxígeno en el agua.

Sistemas anaerobios: En este caso el aceptor de electrones puede ser el $\mathrm{CO}_{2}$ o parte de la propia materia orgánica, obteniéndose como producto de esta reducción el carbono es su estado más reducido, $\mathrm{CH}_{4}$. La utilización de este sistema, tendría, como ya se explicará, como ventaja importante, la obtención de un gas combustible.

Sistemas anóxicos: Se denominan así los sistemas en los que la ausencia de $\mathrm{O}_{2}$ y la presencia de $\mathrm{NO}_{3}$ - hacen que este último elemento sea el aceptor de electrones, transformándose, entre otros, en $\mathrm{N}_{2}$, elemento completamente inerte. Por tanto es posible, en ciertas condiciones, conseguir una eliminación biológica de nitratos (desnitrificación).

Teniendo en cuenta todos estos aspectos, existe una gran variedad de formas de operar, dependiendo de las características del agua, así como de la carga orgánica a tratar.

\subsection{Bioconversión microbiana}

Proceso de transformación bioquímica de un material recuperable contaminado hasta originar nuevas moléculas que constituyen un complejo Mineral Orgánico, con funciones ecológicas definidas. Optimizando el hábitat de los microorganismos, estimulando su desarrollo, 
cuantificando las variables que nos indiquen la orientación de los procesos y que permitan corregir las posibles desviaciones hasta asegurar un control de calidad del producto final.

El proceso se inicia con la descripción analítica del desecho. Al caracterizar el desecho se puede determinar cuál es su uso potencial y la ruta de procesos a seguir. En esta etapa se inician las formulaciones a seguir, fuentes orgánicas e inorgánicas y sus cantidades. Al producirse la mezcla de cada componente, se inicia el conjunto de reacciones bioquímicas de descomposición y composición a seguir durante el proceso. Es importante definir las variables a medir durante el proceso: $\mathrm{pH}$, contenido de aceites y grasas, $\mathrm{CO}_{2}$, $\mathrm{CH}_{4}, \mathrm{O}_{2}$ y temperatura.

\subsubsection{Demanda Bioquímica de Oxígeno}

Expresa la cantidad de oxígeno necesario para la oxidación bioquímica, de los compuestos orgánicos degradables existentes en el líquido residual. Fijando ciertas condiciones de tiempo y temperatura, por ej. en 5 días y a $20{ }^{\circ} \mathrm{C}$. La cantidad de oxígeno consumida durante un tiempo determinado, a una temperatura dada, para descomponer por oxidación las materias orgánicas está en relación directa con la cantidad de materia orgánica. Es una característica cuantificable del grado de contaminación del agua a partir de su contenido de sustancias biodegradables. Ese contenido se expresa en función de la demanda de oxígeno de los microorganismos participantes en la degradación de la materia orgánica presente a $20{ }^{\circ} \mathrm{C}$ en un tiempo predeterminado (usualmente 5 días. DBO5).

\section{MATERIALES Y DESARROLLO EXPERIMEN- \\ TAL}

\section{Muestras}

Los efluentes finales de la curtiembre "Unión S.A." se tomaron en frascos estériles de $1 \mathrm{~L}$. de capacidad y transportados al laboratorio de Bioprocesos Industriales para su caracterización y procesamiento.

\section{Aislamiento y selección de microorganismos}

Se tomó $1 \mathrm{ml}$. del efluente y se procedió a la dilución al décimo hasta llegar a $10^{-5}$ y $10^{-6}$, para luego sembrar una alícuota $(0,1 \mathrm{ml}$.) en medios comunes (agar nutritivo, agar TSA) y en medios selectivos (agar curtiembre). Al cabo de 48 horas de incubación se procedió a aislar las colonias y llevadas a un cepario

Tabla 1. Caracterización promedio de los efluentes de curtiembre

\begin{tabular}{|c|c|}
\hline DETERMINACIÓN & EFLUENTE FINAL \\
\hline $\mathrm{pH}$ & 11,55 \\
\hline Temperatura ${ }^{\circ} \mathrm{C}$ & 20,90 \\
\hline Aceites y grasas mg/l & 9,0 \\
\hline DQO mg/l & 3880 \\
\hline DBO mg/l & 2350 \\
\hline $\begin{array}{c}\text { Sólidos suspendidos } \\
\mathrm{mg} / \mathrm{l}\end{array}$ & 1523 \\
\hline Sulfuros mg/l & 2583,5 \\
\hline
\end{tabular}

Fuente: Análisis fisicoquímico. Laboratorio de Bioprocesos industriales. FCB-UNMSM.

\subsection{Formulación de medios de cultivo}

Teniendo como base el agar curtiembre se formularon 4 medios de cultivo cuya diferencia fundamental fue el $\mathrm{pH}$ y la suplementación.

Tabla 2. Formulación de medios de cultivo

\begin{tabular}{|c|c|c|}
\hline MEDIO & PH & SUPLEMENTACIÓN \\
\hline 01 & 9 & $\mathrm{Ca}_{3}\left(\mathrm{PO}_{4}\right)_{2}$ \\
\hline 02 & 10 & $(\mathrm{NH} 4) 3 \mathrm{PO} 4$ \\
\hline 03 & 11 & $\mathrm{Ca}_{3}\left(\mathrm{PO}_{4}\right)_{2}$ \\
\hline 04 & 12 & $(\mathrm{NH} 4) 3 \mathrm{PO} 4$ \\
\hline
\end{tabular}

Fuente: Manual de medios. Laboratorio de Bioprocesos Industriales. FCB - UNMSM.

\subsection{Evaluación de tolerancia a la alcalinidad}

Las 36 cepas aisladas fueron sembradas en los 4 medios formulados e incubados a $30^{\circ} \mathrm{C}$ por 48 horas, al cabo del cual se determinó crecimiento 


\subsection{Evaluación de la actividad proteolítica y lipolítica}

Las cepas con mejor crecimiento en el medio alcalino de $\mathrm{pH} 12$, fueron sembradas en agar calcio caseinato y agar tributirina para evaluar proteólisis y lipólisis respectivamente. Se incubaron a $35^{\circ} \mathrm{C}$ por 72 horas y se procedió a la verificación y medición de los halos de hidrólisis.

\section{RESULTADOS}

Tabla 3. Caracterización promedio de los efluentes de curtiembre

\begin{tabular}{|c|c|}
\hline DETERMINACIÓN & EFLUENTE FINAL \\
\hline $\mathrm{pH}$ & 11,55 \\
\hline Temperatura $^{\circ} \mathrm{C}$ & 20,90 \\
\hline Aceites y grasas $\mathrm{mg} / \mathrm{l}$ & 9,0 \\
\hline DQO $\mathrm{mg} / \mathrm{l}$ & 3880 \\
\hline DBO $\mathrm{mg} / \mathrm{l}$ & 2350 \\
\hline Sólidos suspendidos mg/l & 1523 \\
\hline Sulfuros $\mathrm{mg} / \mathrm{l}$ & 2583,5 \\
\hline
\end{tabular}

Fuente: Análisis fisicoquímico. Laboratorio de Bioprocesos industriales. FCB - UNMSM.

Figura 1. Porcentaje de crecimiento de cepas en pH 9 y 10.

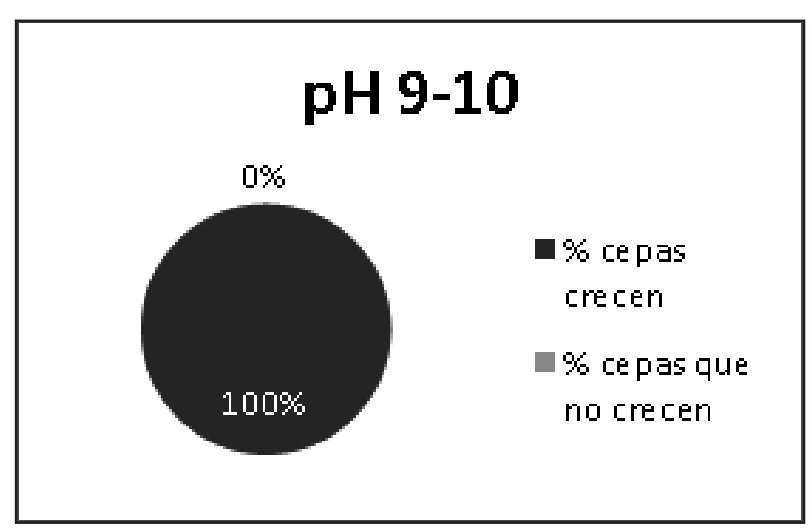

Fuente: Elaboración propia.
Figura 2. Porcentaje de crecimiento de cepas en $\mathrm{pH} 11$.

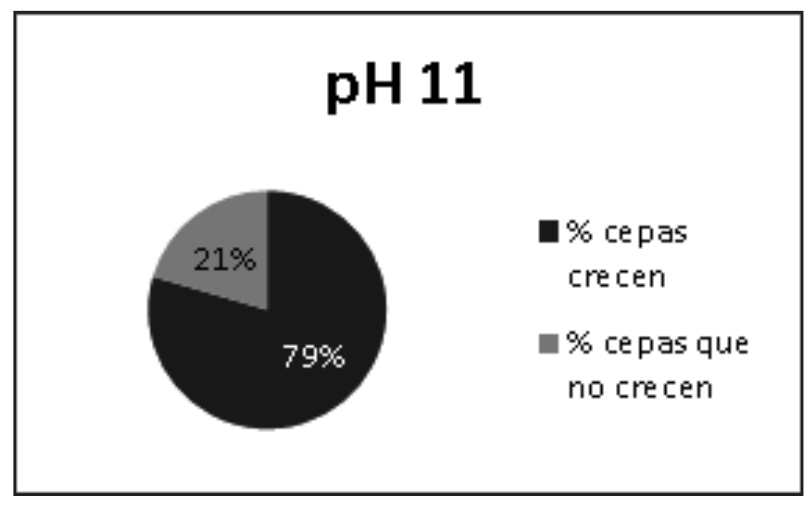

Fuente: Elaboración propia

Figura 3. Porcentaje de crecimiento de cepas en $\mathrm{pH} 12$.

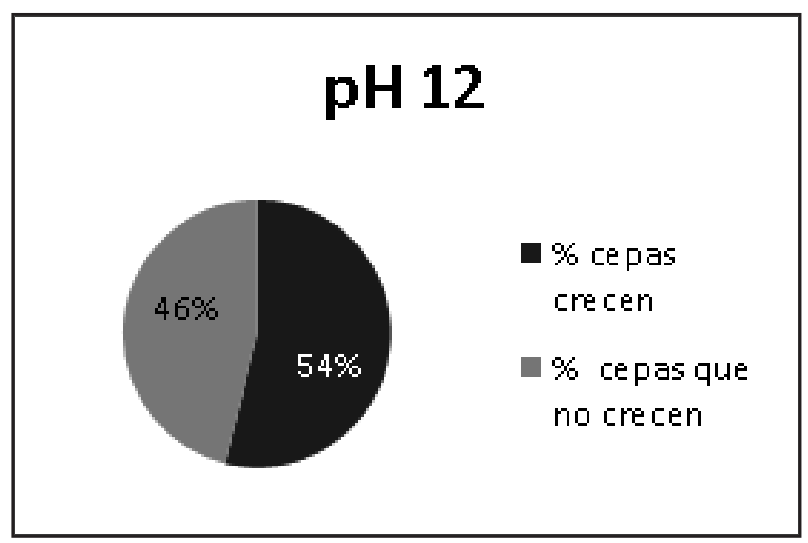

Fuente: Elaboración propia.

\section{Actividad proteolítica}

Figura 4. Actividad proteolítica de cepas tolerantes a $\mathrm{pH} 12$.

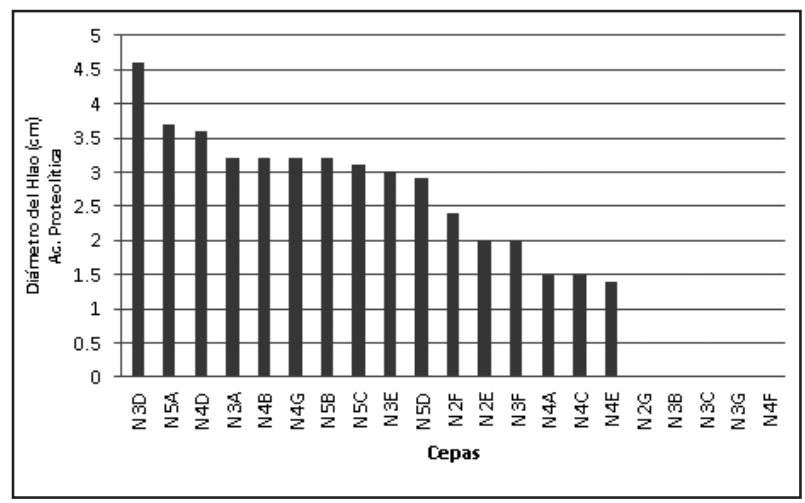




\section{Actividad lipolítica}

Figura 5. Actividad lipolítica de cepas tolerantes a $\mathrm{pH} 12$.

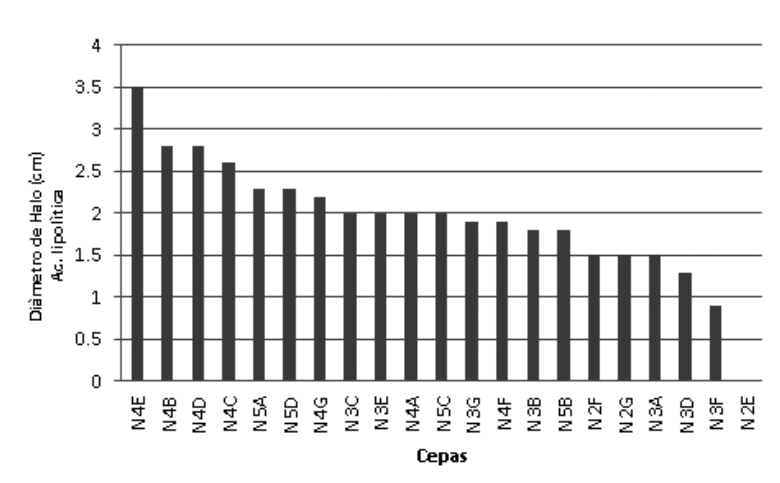

Fuente: Elaboración propia.

\section{DISCUCIONES}

El hallazgo de microorganismos alcalófilos o álcali tolerantes en los efluentes de curtiembre representa una gran importancia para el potencial tratamiento de dichos efluentes por bioprocesos como la bioconversión; pues una de las limitantes para el tratamiento biológico de este tipo de efluentes constituye su característica estresante que limita o bloquea la viabilidad microbiana o la actividad enzimática. Este primer y gran escollo sería superado por los microorganismos aislados (figuras 1-3).

Los altos valores de la DBO reportados en estos efluentes (tabla $N^{\circ} 3$ ) indican altos valores de materia orgánica que superan los límites permisibles impuestos por la norma técnica Peruana (Decreto Supremo 003-2002-PRODUCE), los componentes orgánicos con mayor porcentaje, en los efluentes de curtiembre, corresponden a proteínas y lípidos; por consiguiente su disminución significará un decremento de la DBO y por ende una reducción de su potencial contaminante. Los microorganismos encontrados, tales como la N3D y la N4E han mostrado una gran capacidad de bioconversión de proteínas y lípidos respectivamente, una virtud metabólica requerida para el tratamiento biológico del efluente en estudio.

La utilización de microorganismos autóctonos, aislados de las mismas curtiembres, ofrece mayores ventajas que la utilización de microorganismos alóctonos por el proceso de adaptación, ocurrido en los primeros, a las características y condiciones especiales que los efluentes presentan.
Figura 6. Comparación de actividad proteolítica y lipolítica de las cepas tolerantes a pH 12.

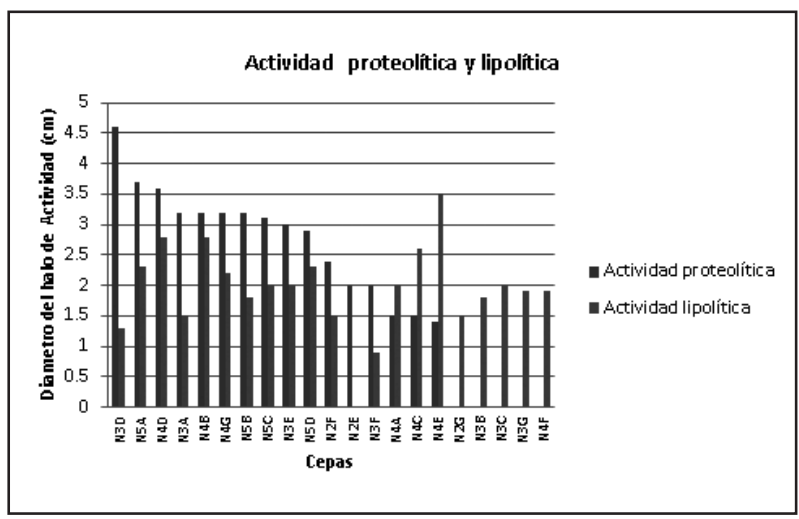

Fuente: Elaboración propia.

\section{CONCLUSIONES}

1. De acuerdo a los resultados en la presente investigación se concluye que los ductos $y$ efluentes de curtiembre contienen microorganismos con actividad proteolítica y lipolítica importante para el tratamiento biológico de efuentes,.

2. Las cepas N3D y la N4E muestran las virtudes metabólicas de interés industrial respecto a las enzimas investigadas y se constituyen en potenciales microorganismos para el tratamiento de efluentes de curtiembre por bioconversión microbiana (fig. 4 y 5 ) y mostraron gran tolerancia a medios de cultivo con $\mathrm{pH} 11-12$.

3. Los microorganismos aislados se encuentran adaptados a las condiciones alcalinas estresantes de dichos efluentes (fig. 1, 2 y 3) y se aislaron cepas con capacidad proteolítica y lipolítica simultáneamente (fig. 6).

\section{BIBLIOGRAFÍA}

[1] Antón de Perino, R. (1990). Complejos de $\mathrm{Cr}$ y Nb c $2-2-(5$ - cloropiridil $)$ - azo -5 - dimetilanimofenol. Aplicaciones analíticas y toxicológicas. (Tesis Doctorado). Universidad Nacional de San Luis. San Luis. Argentina.

[2] AOAC (2005). Association of Official Analytical Chemists. 18th ed. Inc. Washington. D. C. EUA.

[3] Arundel, J. (2002). Tratamiento de Aguas Negras y Efluentes Industriales. Zaragoza. España: Acribia S.A. 
[4] Bollag, D.M. y Edelstein, S.J. (1991). Protein Methods. Nueva York (USA): Wiley-Liss.

[5] Chamy R. Carrera, J. Jeison D. y Ruiz G. (2005). Avances en biotecnología ambiental: Tratamiento de residuos líquidos y sólidos. Pontificia Universidad Católica de Valparaíso. Valparaíso, Chile: Universitarias de Valparaiso S.A,

[6] CITEC-INTI. Centro De Investigaciones De Tecnología Del Cuero (1983). El efluente de Curtiembre; Reutilización de líquidos efluentes. Argentina.

[7] Clesceri L. Greenberg A. Rodees R. (1992). Métodos Normalizados para el Análisis de Aguas Potables y Residuales. American Public Health Association; American Water Works Association; Water Pollution Control Federation. Madrid: Díaz de Santos S. A 17.a ed.

[8] Franson M. ed. (2002). Métodos normalizados para el análisis de aguas potables y residuales. Madrid: Díaz de Santos.

[9] Gerhard Schleenstein (2002). Evaluación de la actividad genotóxica de efluentes de curtiembres del departamento central de la Región Oriental. Revista Virtual Pro.

[10] Lawrence K. (2008). Tratamiento de los Residuos de la Industria. Zaragoza. España: Acribia S.A.

[11] Melga, G (2002). Tratabilidad Aeróbica de un Efluente Proveniente de una Curtiembre de Terminación. XXVIII Congreso Interamericano de Ingeniería Sanitaria y Ambiental. Cancún. México.

[12] Metcalf \& Eddy (1996). Ingeniería en Aguas Residuales; Madrid: Mc Graw Hill; edición 3.

[13] Perry, R. (2000). Manual del Ingeniero Químico; Séptima Edición; Editorial McGraw-Hill; Revista de Ciencia y Tecnología. Vol 2, pp. 37-48.

[14] Rodríguez, R. y Fernández, A. (2012). Tratamientos avanzados de aguas residuales industriales. Madrid España: Acribia S.A.

[15] Schneider, A y col. (2003). Disminución De La Demanda Biológica De Oxígeno de efluentes de curtiembres Por Decantación. Santa Fe. Argentina.

[16] Schneider, A.; Flores, H.; Guala, M. (2002). Recuperación de Sulfuros de Efluentes de Curtiembre. Publicado en Actas del $12^{\circ}$ Congreso Argentino de Saneamiento y Medio Ambiente.

[17] Skoog, D.; West, D. (2006). Fundamentals of Analytical Chemistry; Saunders College Publishing -Harcourt College Publishers.

[18] Stuart Miller (1999). Informe para el Ministerio de Industria y Turismo, Integración y Comercio Internacional (MITINCI). Lima Perú.

[19] Umaña Bustamante, R. (2004). Tratamiento de Aguas Residuales de la Industria de la Curtiembre Mediante un Sistema de Lodos Activados a Escala Piloto. (Tesis Maestría) Universidad de la Frontera. Temuco, Chile. 